\title{
Hormones in sports: growth hormone abuse
}

\author{
Evanthia Diamanti-Kandarakis, Dimitrios Tsilakis, Stefanos Lazarides, Helen Kandar- \\ akis, Angeliki Bergele
}

\section{Endocrine Section, First Department of Medicine, Medical School, University of Athens, Athens, Greece}

\section{General considerations}

"Altius, citius, fortius": higher, faster, stronger. These words from ancient times still today express the endeavour of athletes to beat records and gain victory. This endeavour has never been easy and becomes harder every day as the records climb higher. Many athletes are thus tempted to use artificial substances that enhance power, stamina and body structure.

Doping has been in existence since the advent of sports and competitive games, but has developed into a real epidemic in our times, supported by the breathtaking advances of medical and pharmaceutical sciences. Elite-class athletes experiment with performance-enhancing substances that remain undetected, growth hormone $(\mathrm{GH})$ being one of them. The world champion, Ben Johnson, was one of several athletes who admitted to having taken $\mathrm{GH}$ for several years, in combination with anabolic-androgenic steroids (AAS). The issue of GH abuse became a major problem in the last Olympic Games in Sydney where large quantities of human $\mathrm{GH}$ were stolen from a wholesale pharmacy. Moreover, there have been reports of GH abuse among adolescents ${ }^{1}$. Thus, the time has definitely come for the international community to put an end to the era of so-called "risk-free" GH abuse. The efforts made by the International Olympic Committee (IOC), along with the Medical Committee (MC) and the recently developed World Anti-Dop-

Address correspondence and requests for reprints to: Evanthia Diamanti-Kandarakis, Associate Professor of Medicine, Medical School University of Athens, Fax: +302108130031, e-mail: akandara@otenet.gr

Received 29-09-03, Revised 01-11-03, Accepted 02-12-03 ing Agency (WADA), underline the need for a very active anti-Doping campaign ${ }^{2}$.

This review presents a brief account of current data on GH physiology and our understanding of GH abuse in sports. Recent work has opened up a new and exciting area of endocrinology in parallel with the efforts being made to expunge doping from sports.

\section{INTRODUCTION}

\section{Structure of $\mathrm{GH}$ and its receptor}

$\mathrm{GH}$ is synthesized and stored by somatotropes which make up about $50 \%$ of the anterior pituitary hormone-producing cells. $\mathrm{GH}$ is encoded by genes located in the long arm of chromosome 17, whose main product is a single chain, non-glycosylated, 191-aminoacid, 22kDa protein, with two disulfide bonds, which forms $4 \alpha$-helices ${ }^{3}$. Moreover, $\mathrm{GH}$ circulates in various other forms, including a $20 \mathrm{kDa}$-form (accounting for approximately $10 \%$ of total $\mathrm{GH}$ ) and some monomeric and polymeric variants in lesser amounts.

The actions of $\mathrm{GH}$ are mediated by its binding to the specific growth hormone receptor (GHR), a 638aminoacid protein with single extracellular, transmembrane and cytoplasmic domains which belongs to the cytokine/hematopoietin receptor superfamily.

\section{Physiology}

$\mathrm{GH}$ secretion is pulsatile and is regulated by two hypothalamic hormones; GHRH (growth hormone releasing hormone) increasing the transcription of $\mathrm{GH}$ mRNA, and Somatostatin reducing the frequency and amplitude of $\mathrm{GH}$ pulses without interfering with its synthesis. Between pulses GH falls to virtually unde- 
tectable levels in the blood.

Besides the well-established pattern of the regulation of GH secretion by GHRH and somatostatin, a novel pathway of GH secretion has emerged regulated by a new family of GH secretagogues (GHSs). Evidence suggests that GHSs act on somatotrophs through a phospholipase C-inositol triphospate-PKC signaling pathway, distinct from the cAMP-PKA pathway activated by GHRH, and they are much more effective in vivo than in vitro ${ }^{4}$.

Elevated levels of GH are present in physiological and pathological situations. They are elevated at stages III and IV of sleep, in stress, hypoglycemia, fasting, uremia, hepatic cirrhosis, hyperthyroidism and uncontrolled diabetes mellitus, and they are stimulated by GHRH, estrogens, glucagons, some amino acids (leucine and arginine) and decreased IGF-I levels ${ }^{5}$. GH levels reach their peak during puberty. Afterwards, there is a decrease in GH secretion with age, the reduction rate being about $14 \%$ per decade ${ }^{6}$. GH secretion is inhibited by REM sleep, hyperglycemia, rising fatty acid levels, obesity, somatostatin, hypothyroidism, high IGF-I levels and high glucocorticoid levels ${ }^{5}$.

The half-life of the GH molecule in the plasma and after intravenous injection is approximately 1520 minutes. After a subcutaneous or an intramuscular injection, GH levels reach their peak in 1-3 hours and fall to undetectable levels in 24 hours ${ }^{7}$. Like all peptide hormones GH cannot be given by mouth. GH circulates in plasma bound with proteins (GHBPs). One of them is similar to the extramembrane section of the GH receptor and plays an important role in regulating $\mathrm{GH}$ secretion.

The circulating GH is cleared from the bloodstream through receptor mediated degradation, predominantly in the liver and kidney. GH is excreted in the urine in minute quantities. Thus, it is difficult to develop a valuable detecting test of $\mathrm{GH}$ in the urine.

\section{Mode of action}

\section{a) GH effects}

The action of GH is characterized as anabolic and lipolytic. Its major action seems to be the stimulation of protein synthesis. GH appears to be at least as powerful as testosterone in this task, acting through different pathways, and there is possibly a synergy between them. In the case of GH, the mechanism seems to be the mobilization of amino acid transporters in a way similar to insulin and glucose transporters ${ }^{7}$. Thus, GH results in a positive nitrogen balance when administered to normal and obese adults but only on a short-term basis ${ }^{5}$. In addition to stimulating protein synthesis, GH simultaneously mobilizes fat by a direct lipolytic action. Together, these two effects are responsible for the "partitioning" action of GH, whereby it diverts nutritional calories to protein synthesis, possibly through using the energy derived from its lipolytic action.

When administered to children with GH deficiency, it accelerates linear growth and causes a redistribution of fat ${ }^{8}$. The latter effect is more prominent in obese children $^{8}$, while it is insignificant when administered to athletes who already have reduced fat deposits 9

Due to the abundance of its receptors in almost all types of tissue, GH stimulates a variety of metabolic processes in all cells. The best known of its actions is the promotion of synthesis of IGF-I and IGF-II and their binding proteins. In most tissues IGF-I has local, i.e. autocrine and paracrine actions, but the liver actively secretes IGF-I (and its binding proteins) into the circulation. Until recently it was thought that this "hormonally" produced IGF-I was responsible for many of GH's actions in vivo. Recent data from experiments with hepato-specific knock-out mice disclosed that circulating IGF-I should now be considered more as a marker of GH action on the liver rather than a mechanism by which GH exerts its effects?

\section{b) Intracellular Signal Transduction}

It has been postulated that in order to exert its effects, the GH molecule has to bind to two GH receptors forming a receptor dimer, a step thought to be crucial in GH signaling (Figure 1). The pattern of $\mathrm{GH}$ binding to two identical receptors has been revealed by its crystal structure ${ }^{10}$. However, there is now evidence that $\mathrm{GH}$-receptors exist as preformed dimers, their dimerisation occurring in the endoplasmic reticulum and maintained through the transport to the cell membrane ${ }^{11}$. The binding of growth hormone molecule to the receptor dimer induces conformational changes that result in the activation JAK2 (Janus kinase 2), a non-receptor tyrosine kinase ${ }^{11,12}$. The activated JAK2 phosphorylates itself and the cytoplasmic domain of GH receptor on tyrosine residues. These phosphotyrosines form binding sites for signaling pro- 


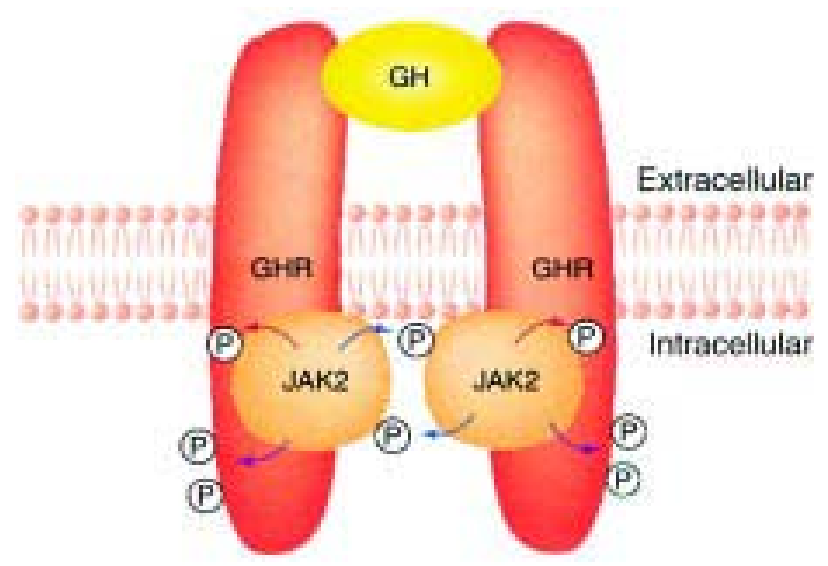

Figure 1. Activation of JAK2 by GH. The two JAK2 molecules, possessing high affinity properties for the $\mathrm{GH}$ receptor, come in close proximity as the GH receptor dimer forms. This results in phosphorylating each others activating tyrosine, thereby turning it into an active form. The activated JAK2 molecule phosphorylates itself and the cytoplasmic domain of the $\mathrm{GH}$ receptor on tyrosine residues. These phosphotyrosines form binding sites for signaling proteins. $\mathrm{GH}$, growth hormone; GHR, growth hormone receptor; JAK2, Janus Kinase 2; P, phosphate. From: Herrington J, Carter-Su C Signaling pathways activated by the growth hormone receptor (14). Redesigned.

teins, including: 1) signal transducers and activators of transcription (Stats), which regulate transcription ${ }^{13}$; 2) SHC proteins, which initiate the Ras-MAP kinase pathway ${ }^{14}$; and 3) insulin receptor substrate (IRS) proteins, which are thought to regulate metabolic events in the cell. In particular, the mechanisms via which GH decreases lipogenesis and increases lipolysis may involve both a STAT-dependent action and a PI3-kinase-dependent activation of a specific phosphodiesterase, while the GH stimulation of protein synthesis is thought to be mediated via specific tyrosines in the cytoplasmic domain of the GHR ${ }^{14}$.

\section{Clinical use of $\mathrm{GH}$}

Growth Hormone is legally prescribed for children with GH deficiency, chronic renal insufficiency prior to renal transplantation, Turner syndrome, PraderWilli syndrome, and small for gestational age children with poor growth ${ }^{15}$. In adults, the approved therapeutic indications are adult GH-deficiency and AIDS-related wasting ${ }^{16}$. Its anabolic properties have justified its administration in severe catabolic conditions such as excessive burns, although a recent study showed increased mortality in patients receiving GH in su- pra-physiological doses in an intensive care unit ${ }^{17}$.

Over the last few years the phenotype of adult GH deficiency has become clear, consisting of decreased lean body mass and bone density, increased fat mass and a reduction in muscle strength and endurance to exercise. The results of a study in which GH was administered to $22 \mathrm{GH}$-deficient adults, at a dose of 2 $\mathrm{IU} / \mathrm{m}^{2}$ for 4 months, showed an increase in lean body mass and in exercise capacity as well as a decrease in fat mass ${ }^{18}$. Heart rate increased both at rest and after maximum exercise while arterial pressure and the echocardiographic wall mass of the left ventricle remained unaltered. Glomerular filtration rate and renal plasma flow increased to a level comparable to an age-matched control group. Finally, GH therapy returned circulating IGF-I levels to normal.

A second trial ${ }^{19}$ studying the effects of administering $\mathrm{GH}$ to $24 \mathrm{GH}$-deficient adults for six months at a dosage of $0.07 \mathrm{IU} / \mathrm{kg} /$ day showed an increase in lean body mass along with a decrease in fat mass by about $20 \%$, while the basal metabolic rate increased significantly. Total cholesterol levels were lower in the $\mathrm{GH}-$ treated group of patients while triglyceride levels remained unaltered. The most common side effect was fluid retention demonstrated by swollen ankles and a sensation of tightness in the hands. In most patients, symptoms disappeared spontaneously, but two of them required dose reduction. $\mathrm{GH}$ has also been shown to increase bone mineral content and density in hypopituitary patients with adult-onset GH deficiency ${ }^{20}$.

Finally, a trial studying the effects of 26 weeks of GH-replacement therapy in $10 \mathrm{GH}$-deficient adults also showed an increase in muscle volume and a decrease in body fat along with redistribution of adipose tissue from visceral to subcutaneous depots, as shown by computerized tomography ${ }^{21}$. The authors suggest that increased visceral fat mass in GH deficiency may be one mechanism behind the increased cardiovascular mortality observed in hypopituitary patients ${ }^{22}$.

As a result, $\mathrm{GH}$ administration to $\mathrm{GH}$-deficient adults has undoubtedly positive effects mainly due to its anabolic and lipolytic actions. The dose is individualized, the mean dose being 1-2 IU/day given by subcutaneous injection ${ }^{23}$. The commonest side effect is fluid retention, which subsides either spontaneously or with a dose reduction. Rarely, an addition of a diuretic agent may be required ${ }^{19}$. 


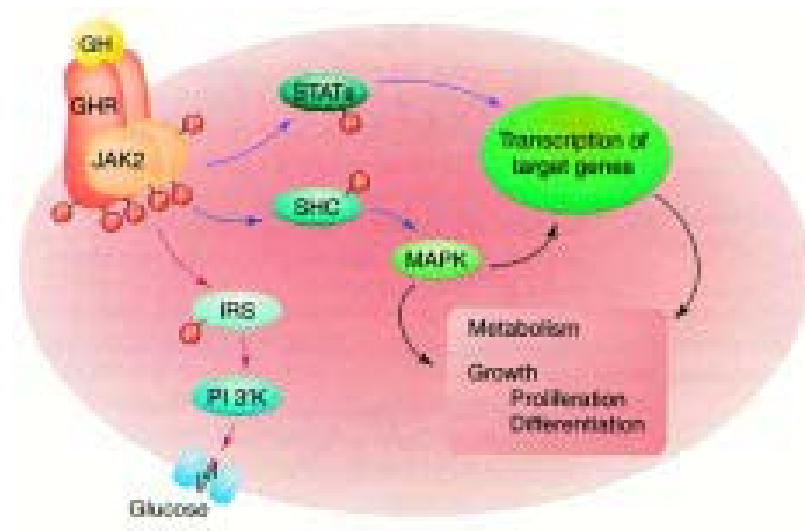

Figure 2. GH- post receptor-signaling pathways. JAK2 phosphorylates: 1) several members of the STAT family of transcription factors and 2) the SHC proteins thus activating the MAP-kinase pathway. In these two ways $\mathrm{GH}$ regulates gene transcription. JAK2 also phosphorylates IRS proteins thereby activating PI3kinase, which possesses a central role in glucose transport. GH, growth hormone; GHR, growth hormone receptor; IRS, insulin receptor substrates; JAK2, Janus kinase 2; MAPK, mitogen-activated protein kinase; P, phosphate; PI3`K, phosphatidylinositol 3-kinase; STAT, signal transducers and activators of transcription. From: Herrington J, Carter$\mathrm{Su} \mathrm{C}$ Signaling pathways activated by the growth hormone receptor (14). Redesigned.

\section{GH ABUSE}

It is noteworthy that $\mathrm{GH}$ abuse by athletes had started before $\mathrm{GH}$ was licensed as a substitution therapy for GH-deficient adults. The effects of exercise on the GH/IGF-I axis have been investigated. A large number of studies indicate that GH levels increase 10 minutes after the beginning of training and may increase up to 100 -fold, especially in response to anaerobic exercise and hypoxia ${ }^{24-26}$. Daytime exercise has also been shown to increase GH secretion during sleep ${ }^{27}$. Investigators who studied the effect of training on the GH response to acute exercise have published conflicting results ${ }^{28}$. The exact mechanism remains uncertain, though it seems to be largely dependent on fat and carbohydrate ingestion ${ }^{28}$. The physiological increase in GH levels seen in normal exercise makes it hard to differentiate this increase from that caused by external $\mathrm{GH}$ administration, as in doping situations. The reports of the effect of exercise upon IGF-I have also been conflicting, some of them showing no increase $^{26,29}$, while in others ${ }^{30,31}$ IGF-I was increased in a manner dependent on the exercise intensity.

Increased IGF-I levels rise in response to chronic exercise within two weeks ${ }^{32}$. The question is whether muscle development after systemic training is due to circulating or locally produced IGF-I. The study of GH-suppressed rats showed normal response to training, suggesting that exercise might have stimulated a local increase of IGF-I mRNA ${ }^{33}$. However, a similar study in humans, aged 65-82 years, showed no increase in muscle IGF-I mRNA either in response to training or to concomitant $\mathrm{GH}$ administration ${ }^{34}$, suggesting no direct anabolic effect of GH on muscle protein synthesis.

\section{GH abuse by athletes}

Nowadays, more and more athletes are tempted to use GH as a performance-enhancing substance. It is considered to be efficient, undetectable and without major side effects. Athletes use it to increase their muscle mass and strength. GH is also believed to reduce injuries and to shorten recovery periods between workouts. It seems that it is particularly popular among female athletes since it lacks the androgenic side effects of anabolic-androgenic steroids.

The dose of GH abused by athletes varies, but it is said to be 10-25IU/day, 3-4 times a week. Moreover, $\mathrm{GH}$ is taken for prolonged periods in cycles lasting 612 weeks, although there are athletes abusing it for even longer periods.

However, the trials conducted up to date do not prove GH's reputation as an anabolic substance. In elderly men, over 60 years of age, who had followed a strict training regimen, Taaffe et al ${ }^{34,35}$ did not report increased muscle strength or muscle hypertrophy after administering GH. Neither did they find an increase in mRNA molecules of the GH/IGF-I axis $(\mathrm{GH}$, IGF-I and IGF-II receptors and IGF-I and IGF-II molecules) in muscle tissue. The authors conclude that in healthy, training adults no anabolic response to $\mathrm{GH}$ is observed. A similar lack of difference was reported by Yarasheski et al in older $\mathrm{men}^{36}$ and in young men $^{37}$. The effects of systemic administration of recombinant $\mathrm{GH}(\mathrm{rhGH})$ in restoring exercise capability and muscle strength in GH-deficient adults and the ergogenic benefits of GH doping amongst athletes remain unproven.

Deyssig et al followed 22 young athletes ${ }^{9}$ who received GH or placebo for six weeks and concluded that despite the increase in GH, IGF-I and IGF-binding protein 3, their body weight and fat mass were not changed significantly. Moreover, strength increased 
significantly in both groups ( $\mathrm{GH}$ and placebo). The authors conclude that the anabolic and lipolytic effects of GH therapy in adults depend on fat mass and the presence of GH deficiency. In highly trained athletes who already have reduced fat mass, GH administration has no effect on body composition or on muscle strength.

It has to be mentioned that Jenkins $\mathrm{PJ}^{28}$ in reviewing these studies concluded that the lack of anabolic response of $\mathrm{GH}$ observed was due to the relatively low GH doses and the short periods of use. Moreover, even subtle increase in muscular strength or cardiovascular activity due to $\mathrm{GH}$, that were not detected by methods used by the investigators, could mean a lot at an international competition level. Nevertheless, none of these studies investigated the possible synergistic effects of $\mathrm{GH}$ with anabolic androgenic steroids, often abused simultaneously by athletes, a process called 'stacking'.

Finally, three reviews addressing the issue of GH administration and exercise conclude that no muscle enhancing properties can be attributed to $\mathrm{GH}$ when administered in trained adults ${ }^{38,40}$. Growth hormone does have powerful effects on fat and carbohydrate metabolism, and in particular promotes the metabolic use of adipose tissue triacylglycerol. However, there is no proof that net protein retention is promoted in adults $^{40}$.

\section{Side effects of GH abuse}

The frequent and potentially severe side effects associated with GH doping will be of increasing relevance to endocrinologists. The study of patients suffering from acromegaly points out the potential side effects of GH abuse by athletes. Acromegalic patients have higher mortality rates than the general population $^{41,42}$, mostly due to cardiovascular and respiratory diseases. Thus, they suffer from hypertrophic cardiomyopathy, hypertension and diabetes mellitus and have an increased risk of developing breast and colon cancer $^{42-44}$. A recent trial ${ }^{45}$ showed that supraphysiological doses of GH, resembling those used by athletes, administered for only four weeks, result in concentric hypertrophy of the left ventricle combined with a high cardiac output state. These findings are associated with increased risk for sudden cardiac death. What is more, a serious effect on the myocardium has been shown in a recent trial, where the concomitant use of
GH and AAS was found to increase the left ventricular mass and result in its concentric remodeling ${ }^{46}$.

A large retrospective cohort study $\mathrm{y}^{42}$ has shown that the predominant determinant of outcome (morbidity and mortality) in acromegaly is the post-treatment $\mathrm{GH}$ levels. When these levels do not exceed $2.5 \mu \mathrm{g} / \mathrm{L}$, the overall mortality rate is similar to that in the general population. A case of Hodgkin's lymphoma in a cyclist treated with $\mathrm{GH}$ has also been reported ${ }^{47}$. Furthermore, rhGH abuse for a 6 -week period produced a disturbed lipid pattern with decreased HDL-cholesterol and apolipoprotein A-1 ${ }^{48}$.

Moreover, the fact that GH can only be applied via subcutaneous injections increases the risk of infections such as hepatitis and HIV by contaminated syringes. It has also been reported that due to the high cost of recombinant $\mathrm{GH}$, some athletes prefer to purchase the cheaper cadaveric GH, extracted from human pituitary glands, which is associated with the risk of developing the fatal Creutzfeldt-Jacob disease characterized by progressive gait and balance disturbances and dementia.

Thus, it has been shown that GH abuse has many adverse effects, including fatal ones as well. The maximal dose and duration of $\mathrm{GH}$ administration which could be safe for the athletes has not yet been found, quite apart from the ethical issue of GH abuse. In view of the multiple side effects of GH abuse, it is becoming increasingly clear that endocrinologists are the most appropriately trained physicians to deal with $\mathrm{GH}$ administration.

\section{Detecting GH abuse by athletes}

The growing trend of $\mathrm{GH}$ abuse among athletes calls for the immediate development of a specific detection test, possessing the necessary sensitivity and specificity as to be acceptable to the IOC. The major difficulties in achieving this target could be summarised as follows. First, the $22 \mathrm{kDa}$ pituitary molecule of growth hormone and the recombinant human $\mathrm{GH}$ abused by athletes are identical. Secondly, GH secretion is pulsatile, therefore the detection of an abnormally high value could simply be attributed to a spontaneous peak ${ }^{28}$. Moreover, exercise itself constitutes a major stimulus to GH secretion and IGF-I levels increase in response to chronic exercise. Therefore, the normal range for $\mathrm{GH}$ in athletes must be reconsidered since athletes are subject to stress and thus to 
wide variations in GH levels ${ }^{49}$. Furthermore, GH secretion is also influenced by dietary habits such as the nutritional supplements favored by a large number of athletes. Finally, the fact that only minute quantities of $\mathrm{GH}$ appear in the urine makes it very difficult to detect in this sample.

During the last few years, important progress has been made towards the development of a GH detection test. So far, two different approaches have been proposed for developing such a test: 1) the GH-isoform approach, and 2) the GH-marker approach.

$\mathrm{Z}$. Wu et $\mathrm{al}^{50}$ described a method for detecting the $22 \mathrm{kDa}-\mathrm{rhGH}$ based on the fact that growth hormone secreted by the pituitary consists not only of the $22 \mathrm{kDa}$ molecule but also of the $20 \mathrm{kDa}$ as well as other products of gene transcription and post-transcription modifications. Thus, the authors developed two specific sandwich-type immunoassays: assay-1, preferentially recognizing the $22 \mathrm{kDa}$ molecule, and assay-2, recognizing all isoforms derived from the pituitary. Performing both assays in the same serum sample and calculating the ratio between them allows estimation of the relative abundance of $22 \mathrm{kDa}-\mathrm{hGH}$. On testing their method, the authors were able to correctly identify 30 patients receiving rhGH and 125 patients who were not treated with rhGH. Among the latter group, 20 patients were taking GHRH, and the rest constituted random samples taken from the daily laboratory routine program. The fact that there was no overlap between the two groups of patients, that no one was erroneously classified as being treated with $\mathrm{rhGH}$, along with the high reproducibility of the method, led the authors to conclude that it may effectively be used to detect doping with GH. Nevertheless, due to the short half-life of rhGH, the diagnostic window is limited to a maximum of 36 hours, which means that the method can only be used in spontaneous 'out-of-competition' testing.

Therefore, it is not unexpected that some serious doubts regarding the efficacy of this method have been raised $^{51}$. They are based on the fact that $\mathrm{Z}$.Wu et al used the serum samples of patients with low GH treated with rhGH (because they had no endogenous GH secretion and thus they had low results in assay- 2 and maximal results in assay-1), and compared them with random clinical samples or with those taking GHRH (thus maximizing endogenous GH secretion, resulting in high results in assay-2). PJ Jenkins suggested that the results would have been different using the samples of athletes in whom circulating endogenous growth hormone concentrations are already high (high results in assay-2) due to pulsatile secretion and rigorous exercise ${ }^{51}$.

A recent study ${ }^{52}$ testing the GH isoform approach described above showed that the administration of high doses of rhGH to young athletes resulted in an increase in the $22 \mathrm{kDa}$ and total $\mathrm{GH}$ concentrations and a decrease in the $20 \mathrm{kDa}$ and non- $22 \mathrm{kDa}$ isoforms of GH. The latter is believed to have occurred via an IGF-I-mediated negative feedback mechanism. The combination of these results was reliable in detecting exogenous rhGH administration, with a window of opportunity of no more than 24 hours after the last injection.

A different approach to the problem of developing a test for GH abuse is the identification of 'markers', i.e. substances that are regulated by $\mathrm{GH}$ and are therefore increased in the case of abuse. This, in fact, was the approach of the international collaborative project called 'GH 2000' jointly funded by the International Olympic Committee and the European Union.

The study of the responses of the GH-IGF-I axis to exercise, $\mathrm{GH}$ administration and $\mathrm{GH}$ withdrawa ${ }^{53}$ revealed that the IGF-I, IGF-binding protein3 (IGFBP-3) and the acid-labile subunit (ALS) could be used to detect $\mathrm{GH}$ doping because their concentrations remained stable throughout the day, increased only modestly and transiently during acute exercise and showed substantial increments after GH administration. What is more, their disappearance kinetics suggested that detection might be possible for several days after cessation of GH treatment.

A second trial studied the effect of exercise, GH administration and $\mathrm{GH}$ withdrawal on certain markers of bone and collagen turnover ${ }^{54}$. Seventeen aerobically-trained males were studied and the results showed that the response of markers PIIIP (procollagen III $\mathrm{N}$-terminal extension peptide) and ICTP (carboxyterminal cross-linked telopeptide of type I collagen) to exercise is minimal, while to $\mathrm{GH}$ administration it is maximal and persists for up to 96 hours after cessation. The separation of GH and placebo-treated athletes was achieved in up to $87.5 \%$ of cases.

The value of PIIIP as a marker of GH action has been demonstrated in another trial ${ }^{55}$ studying the ef- 
fects of GH on bone and collagen turnover in healthy adults. The results showed that PIIIP increased after GH administration in a dose- and gender-dependent manner, the females being less responsive than the males.

More recent data from the GH-2000 research team $^{7}$ showed that the best discrimination between GH treatment and placebo is achieved by using two markers: IGF-I and PIIIP. A more recent trial studied the effect of $\mathrm{GH}$ administration on several markers such as IGF-I, IGFBP-3 and PIIIP in 15 non-competitive athletes. Although, in general, IGF-I increased more rapidly, the concentrations of IGFBP-3 remained increased for a longer time period. The authors concluded that the use of a single marker is insufficient to detect $\mathrm{GH}$ administration. Rather, the combinations of several parameters using mathematical methods could reveal GH abuse by athletes ${ }^{56}$. Hence, there is a need to construct a reference range of these markers in athletes from different sports, and according to age gender and race. The results have also shown a remarkable stability in the markers' blood levels over time, suggesting that these are most likely genetically determined. As regards the effects of injury upon GH markers, it seems that the bone/collagen ones increase while the hepatic ones decrease ${ }^{7}$. A first step towards the construction of reference ranges for GH-markers was recently published ${ }^{57}$. Several molecules such as GH, GH22kDa, specific components of the GH-IGF-I axis, as well as bone markers, were measured in 117 elite-athletes, of both genders and of selected sports, in response to a maximum exercise test. The authors presented reference ranges for each marker, in each gender at specific time points after the test, which can ultimately be used in the development of a $\mathrm{GH}$-abuse detection test.

\section{CONCLUSION}

The results of the GH-2000 project have clearly shown that a test for $\mathrm{GH}$ abuse is feasible ${ }^{7}$. The complexity of the various factors that influence growth hormone levels in the body fluids have made the scientists' efforts extremely difficult, but at the same time a new, exciting field for the medical community has opened up. The GH-2000 project was initially targeted at providing the test for the Sydney Olympic Games? Efforts are continuing and hopefully it will be ready for the next Olympiad. When the process has been accomplished and the test adopted by the International Olympic Committee, a major goal in the fight against the use of anabolic agents will have been achieved.

\section{REFERENCES}

1. Rickert V, Pawlak-Morello C, Sheppard V, Jay S, 1992 Human Growth Hormone: A New Substance of Abuse among Adolescents? Clin Pediatr 31: 723-726.

2. Duntas LH, Parisis C, 2003 Doping: a challenge to the endocrinologist. A reappraisal in view of the Olympic Games of 2004. Hormones 2: 35-42.

3. Miller WL, Eberhard NL, 1983 Structure and evolution of the growth hormone gene family. Endocr Rev 4: 97130.

4. Kojima M, Hosoda H, Matsuo H, Kangawa K, 2001 Ghrelin: Discovery of the natural endogenous ligand for the growth hormone secretagogue receptor. Trends Endocrinol Metab 13: 118-122.

5. Thorner MO, Vance ML, Laws ER, Horvath E, Kovacs K 1998 Prolactin-Growth Hormone family In: Wilson JD, Foster DW, Kronenberg HM, Larsen PR (eds) Williams Textbook of Endocrinology, W.B.Saunders Company; pp, 256-263.

6. Iranmanesh A, Lizarralde G, Veldhuis JD, 1991 Age and relative adiposity are specific negative determinants of the frequency and amplitude of growth hormone $(\mathrm{GH})$ secretory bursts and the half-life of endogenous $\mathrm{GH}$ in healthy men. J Clin Endocrinol Metab 73: 1081-1088.

7. Sonksen PH, 2001 Insulin, growth hormone and sport. J Endocrinol 170: 13-25.

8. Ascoli M, Segaloff DL 1996 Growth hormone In: Hardman J, Limbird LE (eds) Goodman and Gilman's, The Pharmacological Basis Of Therapeuticsm, McGraw-Hill; pp, 1364-1368.

9. Deyssig R, Frisch H, Blum WF, Waldhor T, 1993 Effect of growth hormone treatment on hormonal parameters, body composition and strength in athletes. Acta Endocrinol 128: 313-318.

10. Kopschick JJ 2001 Growth Hormone In: De Groot LJ, Jameson JL (eds) Endocrinology, W.B. Saunders Company; pp, 389-400.

11. Gent J, Kerkhof P, Roza M, Bu G, Strous GJ, 2002 Ligandindependent growth hormone receptor dimerization occurs in the endoplasmic reticulum and is required for ubiquitin system-dependent endocytosis. Proc Natl Acad Sci USA 99: 9858-9863.

12. Argetsinger LS, Campbell GS, Yang X, et al, 1993: The identification of JAK2 as a growth hormone receptor-associated tyrosine kinase. Cell 74: 237-244.

13. Herrington J, Smit LS, Schwartz J, Carter-Su C, 2000 The role of STAT proteins in growth hormone signaling. Oncogene 19: 2585-2597.

14. Herrington J, Carter-Su C, 2001 Signaling pathways activated by the growth hormone receptor. Trends Endocrinol Metab 12: 252-257.

15. Henwood MJ, Gtrimberg A, Moshang T Jr, 2002 Expand- 
ed spectrum of recombinant human growth hormone therapy. Curr Opin Pediatr 14: 437-442.

16. Iglesias P, Dies JJ, 1999 Clinical applications of recombinant human growth hormone in adults. Expert Opin Pharmacother 1: 97-107.

17. Takala J, Ruokonen E, Webster NR, et al, 1999 Increased mortality associated with growth hormone treatment in critically ill adults. N Engl J Med 341: 785-792.

18. Jorgensen JOL, Pedersen SA, Thuesen L, et al, 1989 Beneficial effects of growth hormone treatment in GH-deficient adults. Lancet 1: 1221-1225.

19. Salomon F, Cuneo RC, Hesp R, Sonksen PH, 1989 The effects of treatment with recombinant growth hormone on body composition and metabolism in adults with growth hormone deficiency. N Engl J Med 321: 1797-1803.

20. Johannsson G, Rosen T, Bosaeus I, Sjostrom L, Bengtsson BA, 1996 Two years of growth hormone treatment increases bone mineral content and density in hypopituitary patients with adult-onset GH deficiency. J Clin Endocrinol Metab 81: 2865-2873.

21. Bengtsson BA, Eden S, Lonn L, et al, 1993 Treatment of adults with growth hormone (GH) deficiency with recombinant human GH. J Clin Endocrinol Metab 76: 309-317.

22. Rosen T, Bengtsson BA, 1990 Premature cardiovascular mortality in hypopituitarism- a study of 333 consecutive patients. Lancet 336: 285-288.

23. Ehrnborg C, Bengtsson BA, Rosen T, 2000 Growth hormone abuse. Baillieres Best Pract Res Clin Endocrinol Metab 14: 71-77.

24. Felsing NE, Brasel JA, Cooper DM, 1992 Effect of low and high intensity exercise on circulating growth hormone in men. J Clin Endocrinol Metab 75: 157-162.

25. Knutdzon J, Bogsnes A, Norman N, 1989 Changes in prolactin and growth hormone levels during hypoxia and exercise. Horm Metab Res 21: 453-454.

26. Kraemer WJ, Aguilera BA, Terada M, et al, 1995 Responses of IGF-I to endogenous increases in growth hormone after heavy-resistance exercise. J Appl Physiol 79: 1310-1315.

27. Kern W, Perras B, Wodick R, Fehm HL, Born J, 1995 Hormonal secretion during nighttime sleep indicating stress of daytime exercise. J Appl Physiol 79: 1461-1468.

28. Jenkins PJ, 1999 Growth hormone and exercise. Clin Endocrinol 50: 683-689.

29. Hellenius ML, Brismar KE, Berglund BH, de Faire UH, 1995 Effects on glucose tolerance, insulin secretion, insulin-like growth factor 1 and its binding protein, IGFBP1 , in a randomized controlled diet and exercise study in healthy, middle-aged men. J Intern Med 238: 121-130.

30. Schwartz AJ, Brasel JA, Hintz RL, Mohan S, Cooper DM, 1996 Acute effect of brief low- and high-intensity exercise on circulating insulin-like growth factor I, II, and IGFbinding Protein-3 and its proteolysis in young healthy men. J Clin Endocrinol Metab 81: 3492-3497.

31. Cappon J, Brasel JA, Mohan S, Cooper DM, 1994 Effect of brief exercise on circulating insulin-like growth factor I. J Appl Physiol 76: 2490-2496.

32. Roelen CA, de Vries WR, Koppeschaar HP, Vernoorn
C, Thijssen JH, Blankenstein MA, 1997 Plasma insulinlike growth factor-I and high affinity growth hormonebinding protein levels increase after two weeks of strenuous physical training. Int J Sports Med 18: 238-241.

33. Cooper DM, Moromisato D, Zanconato S, Moromisato M, Jensen S, Brasel JA, 1994 Effect of growth hormone suppression on exercise training and growth responses in young rats. Pediatr Res 35: 223-227.

34. Taaffe DR, Jin IH, Vu TH, Hoffman AR, Marcus R, 1996 Lack of effect of recombinant human growth hormone $(\mathrm{GH})$ on muscle morphology and GH-Insulin-like growth factor expression in resistance-trained elderly men. J Clin Endocrinol Metab 81: 421-425.

35. Taaffe DR, Pruitt L, Reim J, et al, 1994 Effect of recombinant human growth hormone on the muscle strength response to resistance exercise in elderly men. J Clin Endocrinol Metab 79: 1361-1366.

36. Yarasheski KE, Zachwieja JJ, Cambell JA, Bier DM, 1995 Effect of growth hormone and resistance exercise on muscle growth and strength in older men. Am J Physiol 268: E268-E276.

37. Yarasheski KE, Cambell JA, Smith K, Rennie MJ, Holloszy JO, Bier DM, 1992 Effect of growth hormone and resistance exercise on muscle growth in young men. Am J Physiol 262: E261-E267.

38. Dean H, 2002 Does exogenous growth hormone improve athletic performance? Clin J Sport Med 12: 250-253.

39. Jenkins PJ, 2001 Growth hormone and exercise: physiology, use and abuse. Growth Horm IGF Res 11: Suppl A: 71-7.

40. Rennie MJ, 2003 Claims for the anabolic effects of growth hormone: a case of the emperor's new clothes? Br J Sports Med 37: 100-105.

41. Bengtsson BA, Eden S, Ernest I, Oden A, Sjogren B, 1988 Epidemiology and long-term survival in acromegaly. A study of 166 cases diagnosed between 1955 and 1984. Acta Med Scand 223: 327-335.

42. Orme SM, Mcnally RJ, Cartwright RA, Belchetz PE, 1998 Mortality and cancer incidence in acromegaly: a retrospective cohort study. United Kingdom Acromegaly Study Group. J Clin Endocrinol Metab 83: 2730-2734.

43. Nabarro JD, 1987 Acromegaly. Clin Endocrinol 26: 481512.

44. Jenkins PJ, Fairclough PD, Ricards T, et al, 1997 Acromegaly, colonic polyps and carcinoma. Clin Endocrinol 47: $17-22$.

45. Cittadini A, Berggren A, Longobardi SM, et al, 2002 Supraphysiological doses of $\mathrm{GH}$ induce rapid changes in cardiac morphology and function. J Clin Endocrinol Metab 87: 1654-1659.

46. Karila TA, Karjalainen JE, Mantysaari MJ, Viitasalo MT, Seppala TA, 2003 Anabolic androgenic steroids produce dose-dependant increase in left ventricular mass in power athletes, and this effect is potentiated by concomitant use of growth hormone. Int J Sports Med 24: 337-343.

47. Magnavita N, Toefili L, Leone G, 1996 Hodgkin's lymphoma in a cyclist treated with growth hormone. Am J Hematol 52: 65-66. 
48. Zuliani U, Bernardini B, Catapano A, Campana M, Cerioli G, Spattini M, 1989 Effects of anabolic steroids, testosterone, and HGH on blood lipids and echocardiographic parameters in body builders. Int $\mathbf{J}$ Sports Med 10: 62-66.

49. Armanini D, Faggian D, Scaroni C, Plebani M, 2002 Growth hormone and insulin-like growth factor I in a Sydney Olympic gold medallist. Br J Sports Med 36: 148149.

50. Wu Z, Bidlingmaier M, Dall R, Strasburger CJ, 1999 Detection of doping with human growth hormone. Lancet 353: 895 .

51. Jenkins PJ, 1999 Detection of doping. Lancet 353: 1532.

52. Wallace JD, Cuneo RC, Bidlingmaier M, et al, 2001 Changes in non-22kilodalton $(\mathrm{kDa})$ isoforms of growth hormone $(\mathrm{GH})$ after administration of $22-\mathrm{kDa}$ recombinant human GH in trained adult males. J Clin Endocrinol Metab 86: 1731-1737.

53. Wallace JD, Cuneo RC, Baxter R, et al, 1999 Responses of the growth hormone $(\mathrm{GH})$ and insulin-like growth factor axis to exercise, $\mathrm{GH}$ administration, and $\mathrm{GH}$ withdraw- al in trained adult males: a potential test for $\mathrm{GH}$ abuse in sport. J Clin Endocrinol Metab 84: 3591-3601.

54. Wallace JD, Cuneo RC, Lundberg PA, et al, 2000 Responses of markers of bone and collagen turnover to exercise, growth hormone (GH) administration, and $\mathrm{GH}$ withdrawal in trained adult males. J Clin Endocrinol Metab 85: 124-133.

55. Longobardi S, Keay N, Ehrnborg C, et al, and on behalf of the GH-2000 study group 2000 Growth hormone (GH) effects on bone and collagen turnover in healthy adults and its potential use as a marker of $\mathrm{GH}$ abuse in sports: a double blind placebo-controlled study. J Clin Endocrinol Metab 85: 1505-1512.

56. Kniess A, Ziegler E, Kratzsch J, Thieme D, Muller RK, 2003 Potential parameters for the detection if hGH doping. Anal Bioanal Chem 376: 696-700.

57. Ehrborn C, Lange KHW, Dall R, et al, and on behalf of the GH-2000 Study Group 2000. The Growth Hormone/ Insulin-Like Growth Factor-I Axis Hormones and Bone Markers in Elite Athletes in Response to a Maximum Exercise Test. J Clin Endocrinol Metab 88: 394-401. 